new device was inserted under local anaesthesia, without need for dilation.

Have any Journal readers seen something similar, I wonder?

Anne MacGregor, MD, MFSRH

Associate Specialist, Barts Sexual Health Centre, St Bartholomew's Hospital, Barts Health NHS Trust, London, UK; e.macgregor@qmul.ac.uk

Competing interests None.

J Fam Plan Reprod Health Care 2013;39:64. doi:10.1136/jprhc-2012-100536

\title{
An unusual shaped IUS
}

A 45-year-old nulliparous woman attended for removal and replacement of a levonorgestrel-releasing intrauterine system (IUS) for continued management of dysmenorrhoea. I had placed the IUS some 6 years previously under a cervical block, needing to dilate the tight cervical canal for insertion. The patient's periods had been well controlled. The IUS was easily removed but, as pictured, the arms of the device were sheathed in the everted hormone cylinder (Figure 1). A

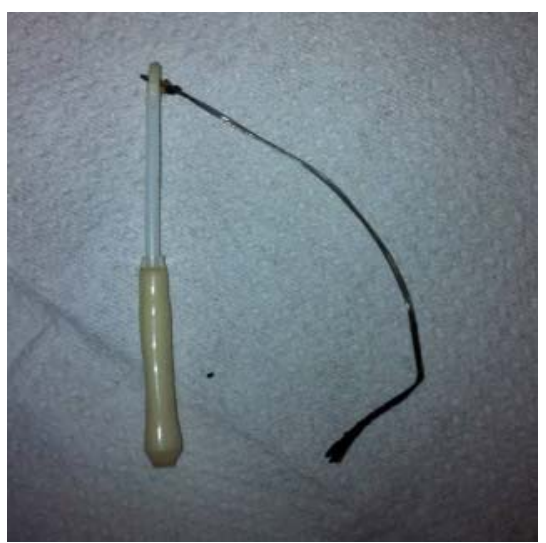

Figure 1 The intrauterine system following removal, showing the arms of the device sheathed in the everted hormone cylinder. 